\title{
Is the UNDP Declared Human Development for Everyone Possible in Real Life?
}

\author{
Vera Komarova, (Dr.oec.) \\ Daugavpils University, Latvia \\ Yuriy Vasserman, ${ }^{3}(\mathrm{PhD})$ \\ Perm National Research Polytechnic University, Russia \\ Natalya Selivanova-Fyodorova, (Doctoral candidate)
}

Daugavpils University, Latvia

Doi:10.19044/esj.2018.v14n32p43～URL:http://dx.doi.org/10.19044/esj.2018.v14n32p43

\begin{abstract}
The law of normal distribution applied to human development states that an equal level of development of countries (regions, and people) at one point in time cannot be achieved, and under any level of average development there will always be those lagging behind this level and those ahead of it. The main research issue within the framework of this article is the following: what happens beyond the average indicators of human development in real life, and is it possible to achieve the equally high level of human development for everyone? The authors answer this question with the help of diachronic and synchronic analysis of the Human Development Index (HDI) in the period 1990 - 2017 with respect to compliance of the HDI variance to normal distribution. Using cluster analysis, the authors obtained the results testifying that the modern world is increasingly divided into groups of countries ("worlds") every one of which has its own average level of human development, and the HDI of the countries within each group varies in accordance with the Gauss curve. These four "worlds" generally coincide with the UNDP division of countries into four groups - very high human development, high human development, medium human development, low human development. The authors came to the conclusion that the human development as the dynamic process is possible. But it is impossible to achieve the same level of human development for everyone without differences in the development levels between several groups of countries (several "worlds") and within one group of countries (one "world").
\end{abstract}

${ }^{3}$ The reported study was funded by RFBR according to the research project № 18-011-00548. 
Keywords: Human Development Index, normal distribution, Gauss curve, cluster analysis, "worlds".

\section{Introduction}

The pivotal point for the question set in the title of this article was determined by, firstly, the name of the Human Development Report 2016 which is published annually by the United Nations Development Programme (UNDP) - "Human Development for Everyone" (UNDP, 2016), and, secondly, the existence - in both physical and social nature - of the law of normal distribution of a large amount of random variables which determines that equal "development for everyone" at one point in time cannot be achieved, and there will always be less developed countries, regions, people, etc. and more developed ones. The Human Development Report 2016 also states that "although the average human development improved significantly across all regions from 1990 to 2015, one in three people worldwide continues to live at low levels of human development, as measured by the Human Development Index" (UNDP, 2016).

Selim Jahan, Director of the Human Development Report Office at the presentation of the Human Development Report 2016 in Stockholm on March 21, 2017 said: "We place too much attention on national averages, which often mask enormous variations in people's lives. In order to advance, we need to examine more closely not just what has been achieved, but also who has been excluded and why" (UNDP, 2017).

Therefore, S.Jahan in his speech determined the main research problem which will be addressed in the framework of this article, specifically: what is happening with human development in the world countries which are located beyond the average indicators and why it is happening in this way and not in another way? The authors made an attempt to answer this question with the help of diachronic (the indicator dynamics in the course of time) and synchronic (the distribution of the indicator at specific points of time) analysis of the Human Development Index in the period 1990-2017 with respect to compliance of the HDI variance to the Gauss curve. Having analyzed the human development in the world countries for a relatively long period, the authors hope to provide a scientifically-based and precise answer to the research issue set in the title of the article: is the UNDP declared human development for everyone possible in real life?

Further the body of the article is organized as follows: the following part discusses the theoretical background and methodology of the study on the variance of the level of human development in the world countries, followed by the description of the research technique. The final part describes the results of the empirical research and their discussion. 


\section{Theoretical Background and Methodology for the Study on the Variance of the Level of Human Development in the World Countries}

The phenomenon of the Gaussian distribution is named after the distinguished German mathematician Carl Friedrich Gauss who lived at the end of the $18^{\text {th }}$ - the middle of the $19^{\text {th }}$ centuries. C.F. Gauss was the scientist who in 1809 formulated the law of normal distribution of errors (published in the Latin language and translated into English after Gauss's death - Davis, 1857) which states: if we draw a probability curve of certain non-determined (i.e. random) processes, the greatest number of results will be close to the average value (see Figure 1).

Figure 1. A graphic model of the law of normal distribution of random variables -

Gauss curve

Source: Davis, 1857.

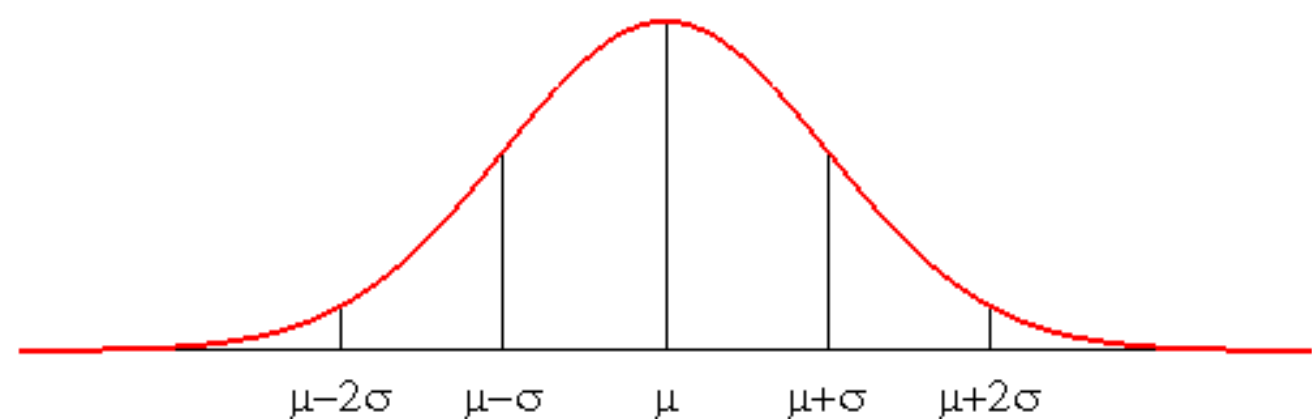

Note:

$\mathrm{N}$ - all values of measured indicator

$\mu$ - mean of measured indicator

$\sigma-$ standard deviation of measured indicator

The area between the curve and the asymptote (see Figure 1) is equal to $\mathrm{N}$; the area of the portion between $\mu-\sigma$ and $\mu+\sigma$ is approximately equal to $2 / 3$ of $N$; between $\mu-2 \sigma$ and $\mu+2 \sigma$ it is approximately $95 \%$ of $N$. According to the so-called "three-sigma rule" (Pukelsheim, 1994) or the "rule 68-95-99.7" common for all curves of normal distribution (Wheeler, Chambers, 1992), almost all values of the measured indicator are placed in the interval of three dispersions. The Gauss curve is always bell-shaped. The normal distribution curves that characterize different indicators of different groups of countries (regions, people, etc.) under study or the indicator of the same group of countries (regions, people, etc.) under study at different points of times can differ only in height and width, whereby, the height of the Gauss curve is the probability of each of the values of the measured indicator (the most probable theoretically is the mathematical expectation or the mean value of the measured indicator, which is at the peak of the Gauss curve), and the width of the "bell" is the dispersion of the values of the measured indicator which is well correlated with the Gini coefficient - the greater the inequality in the measured indicator, the wider the Gauss curve (Lubrano, 2017). 
Application of the law of normal distribution can be found in almost all spheres of modern human knowledge, from physics to philosophy. As a hypothesis of this study, we can assume that the Human Development Index in the world countries is distributed in the same way, i.e. most countries have the HDI close to the world average, a relatively small part of the world countries is developed significantly lower or significantly higher than the world average, and only a few countries stand out against the average level because of their very high or very low HDI.

The Gauss curve can be deformed in one or another direction and represent a different probability, with a different global average value of the HDI and with a different dispersion, i.e. the level of differentiation of the HDI between the world countries.

Measuring social indicators with statistical methods is a fact of the present time, as the society does not stand still - it is constantly moving: developing or degrading. This means that over time, the shape and position of the Gauss curve also changes, moving along the $\mathrm{X}$ - axis in one direction or another: if human development in the world has degraded in general compared to the previous point in time, it will move to the left; if it has improved, it will move to the right. For example, the world on average over a period of time has become more developed by several units of the HDI gradation, which resulted in the fact that those countries which were previously considered highly developed, have become commonplace (i.e., the phenomenon with the highest probability), and those countries which previously had an extremely high level of the HDI have become much more frequent and are no longer something unusual, and countries which were not very developed in the past, are now considered very backward.

A philosophical question also arises: why is normal distribution in nature and in society normal, or commonly found? Why is it fundamentally impossible for all world countries to have similar high levels of human development?

While searching an answer to this question in the modern scientific literature, the authors have come across different approaches to the explanation of the "normality" of the normal distribution - scientists most frequently try to prove mathematically (for example, using the central limit theorem) why, according to what mathematical mechanisms or regularities, random variables are normally distributed (Cramer, 1946 (1961); Feller, 1971; Gregersen, 2010; Mlodinow, 2008). However, only a few of them try to answer the above-stated philosophical question about why nature and society "have chosen" this kind of distribution of random variables as normal.

The philosophy of statistics offers the following answer, which the authors of this article quite agree with: the overall selection pressure determines an ideal norm for something (for instance, people's height or 
intellect), but the selection pressure is not perfect itself, and some variability around the ideal norm will not matter very much. There may even be a selection pressure to maintain some variability to hedge against fluctuating circumstances in the environment. Therefore, in the process of natural selection only the average value (an ideal norm) and the extreme limit of the indicator's variability (in one direction and the other) are strictly fixed. Apart from that, there is no other relevant selection pressure, and the elements of the system (countries, people, animals, cells, etc.) will naturally tend to the state of maximal disorder ${ }^{4}$ - i.e., the state of maximum entropy - subject to its selection constraints. (This is another appeal to something like the second law of thermodynamics). The variance of some measured indicators that maximizes entropy subject to those constraints is a normal distribution, and, so, that is why most indicators in nature and society are normally distributed (Lyon, 2014).

In regard to the level of human development in the world countries it means approximately the following: the world community in the process of its development has achieved an ideal level of development of the country that allows it to function most effectively in the global socio-economic environment. Most countries have achieved this global average level of development, although there are now and there will always be countries on both sides of this "ideal norm". It is necessary for the further development of the system, i.e. world community - the leading countries are testing new forms and ways of functioning in the modern socio-economic environment. If these new forms are viable and potentially productive, the entire world community is striving for them, moving the peak of the Gauss curve to the right along the $\mathrm{X}$-axis to a new global average indicator of countries' development. A group of underdeveloped countries lagging behind is also necessary in the event of a technological catastrophe or non-viability of new forms of countries' functioning in the modern socio-economic environment. Then the world community will have the opportunity to "step back" to the other side of its variable field in order to survive and look for other ways to progress. Therefore, the process of human development resembles the physical process of wave motion on the water surface and it seems to be quite appropriate from a general viewpoint, but not from the viewpoint of countries on the "other side of the variable field", i.e. at the "rear" of development.

\section{Research Technique}

Diachronic (the indicator dynamics in the course of time) and synchronic (the distribution of the indicator at specific points of time) analysis of the Human Development Index (HDI) in the period 1990-2017 with respect to

\footnotetext{
${ }^{4}$ Small children demonstrate it vividly if they are closed in a room for some time.
} 
compliance of the HDI's variance to the Gauss curve served as a methodical basis of the empiric research.

The HDI was created to emphasize that people and their capabilities should be the ultimate criteria for assessing the development of a country, not economic growth alone (see also Seers, 1969; Sen, 1983; World Bank, 1991; Stiglitz, 1994; UN General Assembly, 2000; Boronenko, Lonska, 2013; Lonska, 2014). The HDI is a summary measure of average achievement in key dimensions of human development: a long and healthy life, being knowledgeable and have a decent standard of living (see Figure 2).

The health dimension is assessed by life expectancy at birth, the education dimension is measured by mean of years of schooling for adults aged 25 years and more and expected years of schooling for children of school entering age. The standard of living dimension is measured by gross national income per capita. The HDI uses the logarithm of income, to reflect the diminishing importance of income with increasing Gross National Income (GNI). The scores for the three HDI dimension indices are then aggregated into a composite index using geometric mean (UNDP, 2018a).

Figure 2. The structure of the Human Development Index
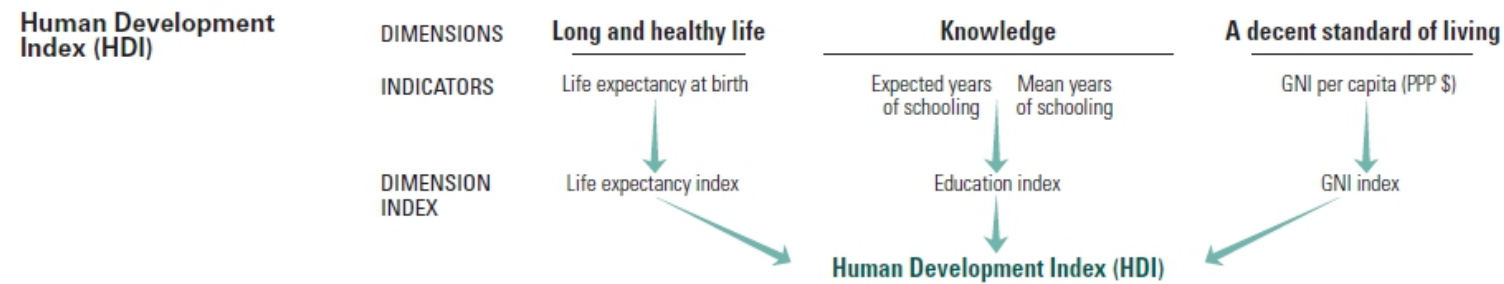

Source: UNDP, 2018a.

In the framework of the given research the authors have analyzed:

1) The dynamics of the average meaning of the Human Development Index for the whole world for the period 1990-2017 (diachronic analysis). A number of countries selected for the analysis changed from 142 countries in 1990 to 189 countries in 2017 in accordance with the UNDP database (UNDP, 2018b). As a rule, during the study period, countries with a sufficiently low level of human development, such as South Sudan, Kiribati, Turkmenistan, Timor-Leste, Uzbekistan, Solomon Islands, etc. were added to the world sample. For the diachronic analysis, the authors decided to take the number of countries for which the UNDP had data in each year of the study period, and not only those countries for which there is information for all 28 years under study. Therefore, a "picture of the human development in the world" was taken in each particular year, including the newly emerged countries in the UNDP database. This analysis allowed the authors to 
find out what is happening with the average value of human development in the world.

2) The parameters of variance of the Human Development Index in the world countries in the period 1990-2017 (diachronic analysis) with respect to compliance of the HDI variance to normal distribution. This analysis allowed the authors to find out, firstly, how the standard deviation of mean of the Human Development Index in the world countries changed over 28 years under study, and, secondly, whether the variance of the Human Development Index corresponded to normal distribution or the Gauss curve and how close this correspondence was.

3) The variance of the Human Development Index in the world countries in 2017 (synchronic analysis) with the application of a cluster analysis and further study of the obtained clusters, specifically, the correspondence of the intra-cluster variance of the Human Development Index to normal distribution, values of mean, minimum, and maximum of the Human Development Index in each cluster. Moreover, the obtained clusters were compared with the existing UNDP division of countries into four groups - very high human development, high human development, medium human development, low human development.

\section{Results of the Empiric Study and Discussion}

Empirical analysis shows that mean of the Human Development Index for the world in the period 1990-2017 grew steadily (see Figure 3), even though, as it is indicated in the description of the research technique in the previous section of the article, the sample of countries during the study period also grew, adding mainly the countries with a low level of human development. Therefore, it is possible to claim that the average level of human development of countries in the world is constantly growing, despite regional and global economic and political crises that took place in the period 1990-2017.

The data presented in Table 1 show parameters of the HDI variance in each year in the period under study. From these data it can be seen, firstly, that the dispersion (i.e. the standard deviation) of the Human Development Index in the world had been slowly but steadily declining over the past 28 years (with the exception of a small increase in the late 1990s). Secondly, the variance of the Human Development Index over all period under study (except for the period 2005-2007) corresponded to the normal distribution (p-coefficient of significance from the Kolmogorov-Smirnov test was always, except for the period 2005-2007, more than 0.05, see Table 1). And yet, in the $21^{\text {st }}$ century this correspondence of the HDI variance in the world countries to the normal distribution is getting weaker (p-coefficient of significance from the Kolmogorov-Smirnov test became considerably closer to the threshold of 0.05 
as compared to the 1990s, see Table 1). In this regard, the authors supposed that the modern world is increasingly divided into groups of countries ("worlds") every one of which has its own average level of human development, and the HDI variance, whose correspondence to normal distribution should be examined.

Figure 3. Dynamics of mean of the Human Development Index for the world, scores, 1990-2017

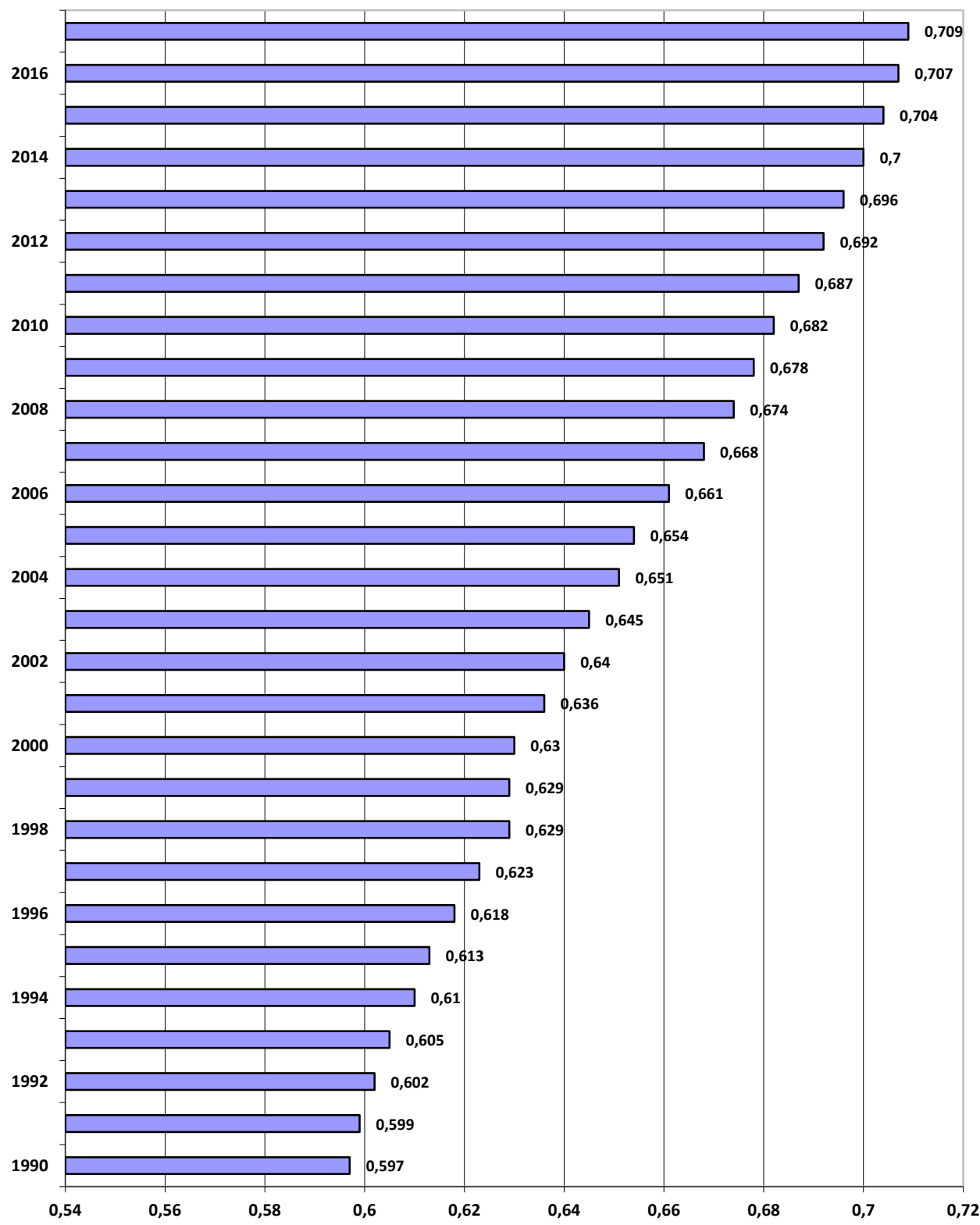

Source: elaborated by the authors using data of the UNDP, $2018 \mathrm{~b}$. 
Table 1. Dynamics of parameters of the Human Development Index variance, 1990-2017

\begin{tabular}{|c|c|c|c|c|c|}
\hline Year & $\begin{array}{l}\text { Average } \\
\text { score, } \\
\text { mean }\end{array}$ & $\begin{array}{l}\text { Standard } \\
\text { deviation }\end{array}$ & $\begin{array}{l}\text { Number of } \\
\text { countries, } n\end{array}$ & $\begin{array}{l}\text { Significance } \\
\text { from the } \\
\text { Kolmogorov- } \\
\text { Smirnov test, } \\
\text { p-coefficient }\end{array}$ & $\begin{array}{l}\text { Decision according the } \\
\text { hypothesis about normal } \\
\text { distribution of HDI } \\
\text { (null hypothesis) }\end{array}$ \\
\hline 1990 & 0.597 & 0.165 & 142 & 0.132 & Retain the null hypothesis \\
\hline 1991 & 0,599 & 0.165 & 143 & 0.184 & Retain the null hypothesis \\
\hline 1992 & 0.602 & 0.165 & 140 & 0.250 & Retain the null hypothesis \\
\hline 1993 & 0.605 & 0.166 & 143 & 0.212 & Retain the null hypothesis \\
\hline 1994 & 0.610 & 0.168 & 143 & 0.389 & Retain the null hypothesis \\
\hline 1995 & 0.613 & 0.167 & 147 & 0.298 & Retain the null hypothesis \\
\hline 1996 & 0.618 & 0.167 & 147 & 0.321 & Retain the null hypothesis \\
\hline 1997 & 0.623 & 0.167 & 147 & 0.351 & Retain the null hypothesis \\
\hline 1998 & 0.629 & 0.168 & 147 & 0.324 & Retain the null hypothesis \\
\hline 1999 & 0.629 & 0.170 & 150 & 0.250 & Retain the null hypothesis \\
\hline 2000 & 0.630 & 0.169 & 172 & 0.114 & Retain the null hypothesis \\
\hline 2001 & 0.636 & 0.168 & 172 & 0.099 & Retain the null hypothesis \\
\hline 2002 & 0.640 & 0.168 & 174 & 0.068 & Retain the null hypothesis \\
\hline 2003 & 0.645 & 0.169 & 176 & 0.067 & Retain the null hypothesis \\
\hline 2004 & 0.651 & 0.166 & 179 & 0.077 & Retain the null hypothesis \\
\hline 2005 & 0.654 & 0.165 & 186 & 0.034 & Reject the null hypothesis \\
\hline 2006 & 0.661 & 0.164 & 186 & 0.025 & Reject the null hypothesis \\
\hline 2007 & 0.668 & 0.162 & 186 & 0.033 & Reject the null hypothesis \\
\hline 2008 & 0.674 & 0.161 & 186 & 0.058 & Retain the null hypothesis \\
\hline 2009 & 0.678 & 0.158 & 186 & 0.055 & Retain the null hypothesis \\
\hline 2010 & 0.682 & 0.157 & 188 & 0.064 & Retain the null hypothesis \\
\hline 2011 & 0.687 & 0.156 & 188 & 0.075 & Retain the null hypothesis \\
\hline 2012 & 0.692 & 0.154 & 188 & 0.064 & Retain the null hypothesis \\
\hline 2013 & 0.696 & 0.154 & 188 & 0.133 & Retain the null hypothesis \\
\hline 2014 & 0.700 & 0.154 & 188 & 0.177 & Retain the null hypothesis \\
\hline 2015 & 0.704 & 0.154 & 188 & 0.187 & Retain the null hypothesis \\
\hline 2016 & 0.707 & 0.154 & 188 & 0.157 & Retain the null hypothesis \\
\hline 2017 & 0.709 & 0.153 & 189 & 0.159 & Retain the null hypothesis \\
\hline
\end{tabular}

Source: elaborated by the authors using data of the UNDP, $2018 \mathrm{~b}$.

The authors' assumption about the presence of several rather isolated and different in terms of the level of human development "worlds" in the modern world is confirmed by the presence of several extrema in the overall picture of the HDI variance in 2017 (see Figure 4). 
Figure 4. Variance of the Human Development Index for the world countries, scores, $\mathbf{n}=189$ countries, 2017

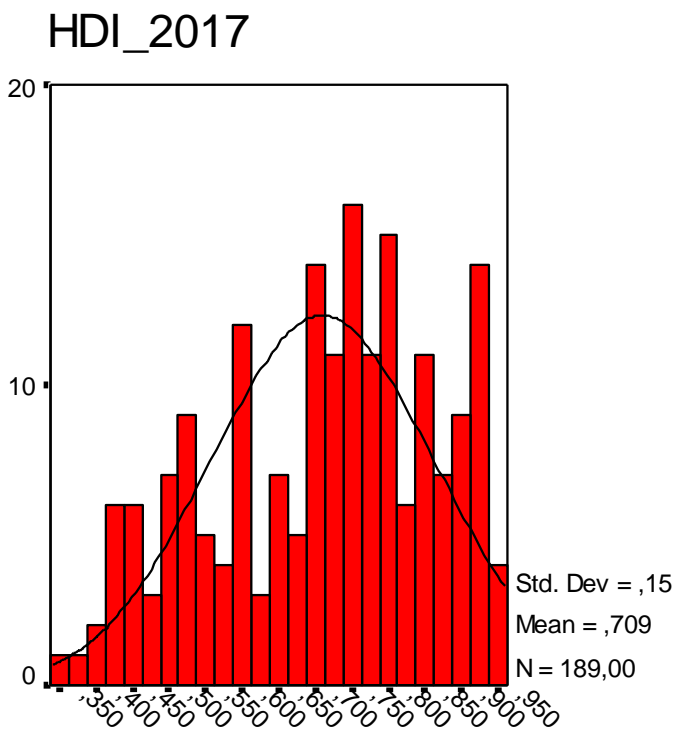

HDI_2017

Source: elaborated by the authors using data of the UNDP, $2018 \mathrm{~b}$.

The cluster analysis carried out by the authors showed that the abrupt increase in the coefficient occurs after the $185^{\text {th }}$ step in the process of agglomeration of cases (i.e. countries) (see Table 2). Therefore, the number of clusters, i.e. "worlds" in the sample of 189 countries is determined by the difference between 189 and 185, i.e. four clusters or four "worlds".

Table 2. Last coefficients from the agglomeration schedule of the cluster analysis of countries by their Human Development Index, $n=189$ countries, 2017

\begin{tabular}{|l|c|c|c|c|c|}
\hline Year & $\begin{array}{c}\text { Fourth } \\
\text { before the } \\
\text { last } \\
\text { coefficient }\end{array}$ & $\begin{array}{c}\text { Third } \\
\text { before the } \\
\text { last } \\
\text { coefficient }\end{array}$ & $\begin{array}{c}\text { Second } \\
\text { before the } \\
\text { last } \\
\text { coefficient }\end{array}$ & $\begin{array}{c}\text { First before } \\
\text { the last } \\
\text { coefficient }\end{array}$ & $\begin{array}{c}\text { Last } \\
\text { coefficient }\end{array}$ \\
\hline $\mathbf{2 0 1 7}$ & 0.302 & 0.374 & 0.805 & 1.136 & 3.853 \\
\hline $\begin{array}{l}\text { No. } \\
\text { of the } \\
\text { step }\end{array}$ & 184 & 185 & 186 & 187 & 188 \\
\hline
\end{tabular}

Source: elaborated by the authors using data of the UNDP, $2018 \mathrm{~b}$.

Table 3 presents the main parameters of the "worlds" obtained as a result of the cluster analysis. Thus, 19 out of 189 countries with a mean of the 
Human Development Index equal to 0.432 and a standard deviation equal to 0.035 got into the "world" with a very low level of human development. In Figures 5 and 6 this "world" is located on the far left on the X-axis, i.e. the most underdeveloped out of the four "worlds"". 40 out of 189 countries with a mean of the Human Development Index equal to 0.558 and a standard deviation equal to 0.042 got into the next "world" with a low level of human development. In Figures 5 and 6 this "world" is located to the right on the Xaxis in relation to the most underdeveloped "world", i.e. it is located already at a higher stage of human development. And so on to the most highly developed "world" which includes 46 out of 189 countries (see Table 3 and Figures 5 and 6).

Thereby, according to the theoretical background and methodology of the study on the variance of the level of human development in the world countries, the authors, on the basis of the synchronic analysis of the HDI in the world countries in 2017 received several variances of the Human Development Index at one point in time. Variances of the HDI in all four "worlds" even more than the variance of the common HDI in the world correspond to normal distribution (see p-coefficients of significance from the Kolmogorov-Smirnov test for clusters in the Table 3). Any world country has a highest probability to enter the cluster/"world" with medium human development, and this fact also corresponds to the law of normal distribution (see Figure 6).

Table 3. Parameters of clusters/"worlds" created applying the cluster analysis to the Human Development Index of countries, $\mathbf{n = 1 8 9}$ countries, 2017

\begin{tabular}{|c|c|c|}
\hline Clusters & $\begin{array}{l}\text { Number of countries and } \\
\text { parameters of variances }\end{array}$ & $\begin{array}{l}\text { Significance from the } \\
\text { Kolmogorov-Smirnov test, } \\
\text { p-coefficient }\end{array}$ \\
\hline $\begin{array}{c}\text { Cluster 1: } \\
\text { Countries with very low } \\
\text { human development }\end{array}$ & $\begin{array}{c}19 \text { countries } \\
\text { mean: } \mathbf{0 . 4 3 2} \\
\text { std. deviation: } 0.035 \\
\end{array}$ & $\begin{array}{c}\text { p-significance of K-S Test: } \\
\mathbf{0 . 8 6 2}\end{array}$ \\
\hline $\begin{array}{c}\text { Cluster 2: } \\
\text { Countries with } \\
\text { low human development }\end{array}$ & $\begin{array}{c}40 \text { countries } \\
\text { mean: } \mathbf{0 . 5 5 8} \\
\text { std. deviation: } 0.042 \\
\end{array}$ & $\begin{array}{c}\text { p-significance of K-S Test: } \\
\mathbf{0 . 4 7 1}\end{array}$ \\
\hline $\begin{array}{c}\text { Cluster 3: } \\
\text { Countries with } \\
\text { medium human } \\
\text { development }\end{array}$ & $\begin{array}{c}84 \text { countries } \\
\text { mean: } \mathbf{0 . 7 4 3} \\
\text { std. deviation: } 0.050\end{array}$ & $\begin{array}{c}\text { p-significance of K-S Test: } \\
\mathbf{0 . 7 1 1}\end{array}$ \\
\hline $\begin{array}{c}\text { Cluster 4: } \\
\text { Countries with } \\
\text { high human development }\end{array}$ & $\begin{array}{c}46 \text { countries } \\
\text { mean: } \mathbf{0 . 8 9 4} \\
\text { std. deviation: } 0.035 \\
\end{array}$ & $\begin{array}{c}\text { p-significance of K-S Test: } \\
\mathbf{0 . 4 6 8}\end{array}$ \\
\hline
\end{tabular}

Source: elaborated by the authors using data of the UNDP, $2018 \mathrm{~b}$.

The theoretical and methodological part of the article describes the situation about changes in the average level of countries' human development - degradation or progress - over time. In the course of the empirical research, the authors obtained results which confirm the fact that there is a continuous 
progress of human development in the world, i.e. the Gauss curve in each subsequent year of the period under study shifted to the right along the X-axis. At the same time, the modern world is divided into qualitatively and quantitatively different "worlds" (see also Komarova, 2016) also at each individual moment of time - for example, in 2017. This is shown in a graphic form by the presence of several Gauss curves simultaneously on one X-axis (see Figure 5), each of which has its own parameters, i.e. mean and standard deviation. Therefore, while studying real social phenomena, it is possible to obtain a whole series of the Gauss curves which characterize the phenomenon under study (in our case - HDI variance) both in dynamics and in a static state.

Figure 5. Variance of the Human Development Index in the four "worlds",

Scores, $\mathbf{n}=189$ countries, 2017

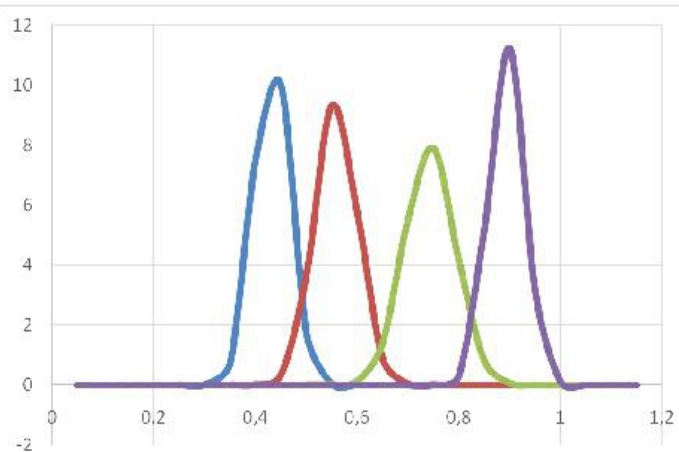

Note: from the left to the right - "world" with very low human development, "world" with low human development, "world" with medium human development, "world" with high human development.

Source: elaborated by the authors applying cluster analysis for the data of the UNDP, $2018 \mathrm{~b}$.

Figure 6. Variance of clusters/“worlds" of countries, 2017

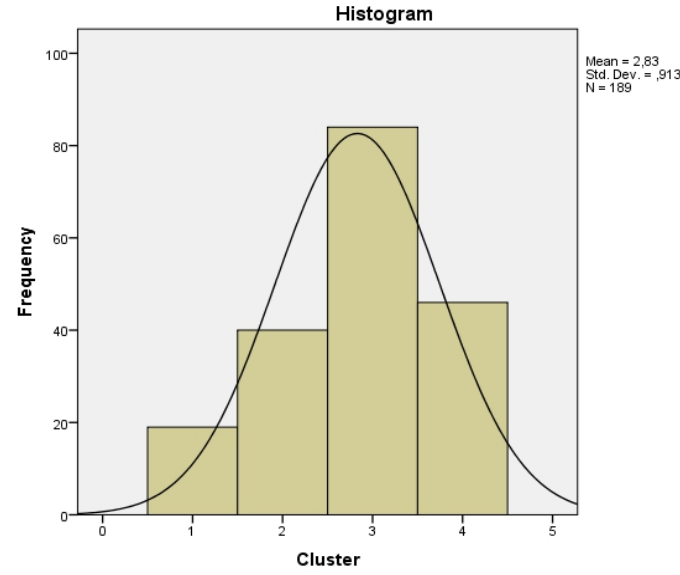

Note: from the left to the right - cluster/“"world" with very low human development, cluster/“"world" with low human development, cluster/"world" with medium human development, cluster/"world" with high human development.

Source: elaborated by the authors applying cluster analysis for the data of the UNDP, $2018 \mathrm{~b}$. 
The "worlds" obtained by the authors in the result of the cluster analysis correspond to the existing UNDP division of countries into four groups with a little difference in emphasis. The UNDP distinguishes very high human development and high human development, not singling out separate groups in the group of countries with low human development. The UNDP's division is quite mechanical, although in general it adequately reflects the real division of countries according to the level of human development. The following Table provides a comparison of the UNDP's classification and authors' classification made on the basis of cluster analysis.

Table 4. Comparison of the authors' "worlds" and the UNDP's groups of countries, $\mathrm{n}=189$ countries, 2017

\begin{tabular}{|c|c|c|c|}
\hline $\begin{array}{l}\text { Authors" "worlds" } \\
\text { of countries }\end{array}$ & \multicolumn{2}{|c|}{$\begin{array}{c}\text { No of countries, } \\
\text { mean, minimum and maximum, } \\
\text { significance from the Kolmogorov- } \\
\text { Smirnov test (p-coefficient) }\end{array}$} & $\begin{array}{l}\text { UNDP's groups } \\
\text { of countries }\end{array}$ \\
\hline $\begin{array}{l}\quad \text { "World" 1: } \\
\text { Countries with very } \\
\text { low human } \\
\text { development }\end{array}$ & $\begin{array}{l}19 \text { countries } \\
\text { Mean } \mathbf{0 . 4 3 2} \\
\text { Min } \mathbf{0 . 3 5 4} \\
\text { Max } \mathbf{0 . 4 7 7} \\
\text { p-significance of } \\
\text { K-S Test: } \mathbf{0 . 8 6 2}\end{array}$ & $\begin{array}{l}38 \text { countries } \\
\text { Mean } \mathbf{0 . 4 7 5} \\
\text { Min } \mathbf{0 . 3 5 4} \\
\text { Max } \mathbf{0 . 5 4 6} \\
\text { p-significance of } \\
\text { K-S Test: } \mathbf{0 . 3 9 4}\end{array}$ & $\begin{array}{l}\quad \text { Group 1: } \\
\text { Countries with low } \\
\text { human } \\
\text { development }\end{array}$ \\
\hline $\begin{array}{l}\text { "World" 2: } \\
\text { Countries with } \\
\text { low human } \\
\text { development }\end{array}$ & $\begin{array}{l}40 \text { countries } \\
\text { Mean } \mathbf{0 . 5 5 8} \\
\text { Min } \mathbf{0 . 4 9 2} \\
\text { Max } \mathbf{0 . 6 2 7} \\
\text { p-significance of } \\
\text { K-S Test: } \mathbf{0 . 4 7 1}\end{array}$ & $\begin{array}{l}39 \text { countries } \\
\text { Mean } \mathbf{0 . 6 3 0} \\
\text { Min } \mathbf{0 . 5 5 6} \\
\text { Max } \mathbf{0 . 6 9 9} \\
\text { p-significance of } \\
\text { K-S Test: } \mathbf{0 . 5 7 9}\end{array}$ & $\begin{array}{l}\quad \text { Group 2: } \\
\text { Countries with } \\
\text { medium human } \\
\text { development }\end{array}$ \\
\hline $\begin{array}{l}\quad \text { "World" 3: } \\
\text { Countries with } \\
\text { medium human } \\
\text { development }\end{array}$ & $\begin{array}{l}84 \text { countries } \\
\text { Mean } \mathbf{0 . 7 4 3} \\
\text { Min } \mathbf{0 . 6 4 0} \\
\text { Max } \mathbf{0 . 8 2 5} \\
\text { p-significance of } \\
\text { K-S Test: } \mathbf{0 . 7 1 1} \\
\end{array}$ & $\begin{array}{l}53 \text { countries } \\
\text { Mean } \mathbf{0 . 7 5 0} \\
\text { Min } \mathbf{0 . 7 0 0} \\
\text { Max } \mathbf{0 . 7 9 8} \\
\text { p-significance of } \\
\text { K-S Test: } \mathbf{0 . 7 6 9}\end{array}$ & $\begin{array}{l}\text { Group 3: } \\
\text { Countries with } \\
\text { high human } \\
\text { development }\end{array}$ \\
\hline $\begin{array}{l}\text { "World" 4: } \\
\text { Countries with } \\
\text { high human } \\
\text { development }\end{array}$ & $\begin{array}{l}46 \text { countries } \\
\text { Mean } \mathbf{0 . 8 9 4} \\
\text { Min } \mathbf{0 . 8 3 1} \\
\text { Max } \mathbf{0 . 9 5 3} \\
\text { p-significance of } \\
\text { K-S Test: } \mathbf{0 . 4 6 8} \\
\end{array}$ & $\begin{array}{l}59 \text { countries } \\
\text { Mean } \mathbf{0 . 8 7 5} \\
\text { Min } \mathbf{0 . 8 0 0} \\
\text { Max } \mathbf{0 . 9 5 3} \\
\text { p-significance of } \\
\text { K-S Test: } \mathbf{0 . 4 3 9} \\
\end{array}$ & $\begin{array}{l}\quad \text { Group 4: } \\
\text { Countries with } \\
\text { very high human } \\
\text { development }\end{array}$ \\
\hline
\end{tabular}

Source: elaborated by the authors using data of the UNDP, $2018 \mathrm{~b}$.

As the results of the comparison between the authors' "worlds" and groups of countries according to the UNDP classification, in both cases the variance of the HDI is closer to the normal distribution than in the whole range of 189 countries, as the significance from the Kolmogorov-Smirnov test ( $p$ coefficient) in both "worlds" and the UNDP groups is much higher than in the whole range (see Table 4). The two classifications that are compared differ 
mainly in relation to the first two groups with the lowest level of human development. The UNDP's approach can be called more "optimistic", uniting countries with very low and low levels of human development into one group. It is interesting that exactly this group - the first one in the UNDP's classification - is the least consistent with the normal distribution as compared to all other groups in both classifications ( $\mathrm{p}$-coefficient equal to 0.394, see Table 4). The UNDP, in turn, distinguishes a group with a very high level of human development and does not distinguish a group with a very low level, in this way to some extent disguising a very difficult situation with human development in some countries, i.e. in the "world" with very low human development.

\section{Conclusion}

1) the human development as a dynamic process is possible for everyone, and in reality, the world average level of human development of countries in the period 1990-2017 had steadily increased;

2 ) the variance of the HDI every year within this period (excluding only 2005-2007) accords with the normal distribution - so, under any static average level of human development there are countries lagging behind this level and ones ahead of it;

3 ) the modern world is divided into groups of countries - separate "worlds", each with its own average level of human development and its variance of the HDI, corresponding to the normal distribution at each stage of human development;

4) it is objectively impossible to achieve the equally high level of human development without differences in the development levels between several groups of countries (several "worlds") and within one group of countries (one "world");

5) since equal "development for everyone" at one point in time is not yet achievable in real life, the situation when the less developed "rear" (especially the "world" of countries with a very low level of human development) will have higher growth rates of the HDI, graphically narrowing the Gauss curve on the total array of countries or bringing the Gauss curve of the least developed countries to the curve of the most developed ones can be considered the greatest achievement of the humanity.

\section{References:}

1. Boronenko, V., \& Lonska, J. (2013). Rethinking territory development in global comparative researches. European Scientific Journal, Vol. 2, pp. 52-62. 
2. Cramer, H. (1946). Mathematical Methods of Statistics. Asia Publishing House. (Ninth Printing, 1961).

3. Davis, C. H. (1857). Theory of the Motion of the Heavenly Bodies Moving about the Sun in Conic Sections: A Translation of Gauss's "Theoria Motus". Boston: Little, Brown and Company.

4. Feller, W. (1971). An Introduction to Probability Theory and Its Applications. Vol. 2. John Wiley \& Sons and Mei Ya Publications.

5. Gregersen, E. (Ed.) (2010). The Britannica Guide to Statistics and Probability. Rosen Education Service.

6. Komarova, V. (2016). Many "Developments" in One World. LAP LAMBERT Academic Publishing.

7. Lonska, J. (2014). Assessment of Territorial State of Development in Latvian Regions. Doctoral Thesis. Daugavpils: Daugavpils University.

8. Lubrano, M. (2017). Lorenz curves, the Gini coefficient and parametric distributions. The Econometrics of Inequality and Poverty. Retrieved from: http://www.vcharite.univ-mrs.fr/PP/lubrano/cours/Lecture4.pdf (accessed on October 20, 2018).

9. Lyon, A. (2014). Why are normal distributions normal? The British Journal for the Philosophy of Science, Vol. 65, No. 3, pp. 621-649.

10. Mlodinow, L. (2008). The Drunkard's Walk. New York: Pantheon Books.

11. Pukelsheim, F. (1994). The Three Sigma Rule. American Statistician, Vol. 48, pp. 88-91.

12. Seers, D. (1969). The Meaning of Development. IDS Communication series, Institute of Development Studies, No. 44, pp. 1-26. Retrieved from:

http://www.ids.ac.uk/files/dmfile/themeaningofdevelopment2.pdf (accessed on October 20, 2018).

13. Sen, A. (1983). Development: Which way now? Economic Journal, Vol. 372, No. 93, pp. 742-762.

14. Stiglitz, J. E. (1994). Economic growth revisited. International and Corporate Change, Vol. 3, No. 1, pp. 65-110.

15. UNDP (2016). Human Development Report 2016: Human Development for Everyone. New York: UNDP.

16. UNDP (2017). World's Most Marginalized Still Left Behind by Global Development Priorities UNDP Report. Retrieved from: http://hdr.undp.org/en/content/world\%E2\%80\%99s-mostmarginalized-still-left-behind-global-development-priorities-undpreport (accessed on October 20, 2018).

17. UNDP (2018a). Human Development Index (HDI). Retrieved from: http://hdr.undp.org/en/content/human-development-index-hdi (accessed on October 20, 2018). 
18. UNDP (2018b). Human Development Data (1990-2017). Retrieved from: http://hdr.undp.org/en/data/trends\# (accessed on October 20, 2018)

19. UN General Assembly (2000). United Nations Millennium Declaration, 18 September 2000. Retrieved from: http://www.unmillenniumproject.org/documents/ares552e.pdf (accessed on October 20, 2018).

20. Wheeler, D. J., \& Chambers, D. S. (1992). Understanding Statistical Process Control. SPC Press.

21. World Bank (1991). World Development Report 1991: The Challenge of Development. New York: Oxford University Press. 